\title{
Santa María de la Antigua del Darién, la primera ciudad española en Tierra Firme: una prospección arqueológica sistemática
}

Santa María de la Antigua del Darién, the First Spanish City in Terra Firma: A Systematic Archaeological Prospection

\author{
Alberto Sarcina \\ Instituto Colombiano de Antropología e Historia (ICANH) \\ abbaziante@iol.it
}

\section{RESUMEN}

En el año 1510 se fundó Santa María de la Antigua del Darién, la primera ciudad española en Tierra Firme. En el 2013, el ICANH inició un Plan de Manejo y Protección de este sitio. En la primera etapa los principales objetivos arqueológicos fueron identificar y delimitar el área de la ciudad y comprobar - refutar la hipótesis de si Bahía La Gloria fue el puerto de la ciudad. Las evidencias de prospecciones por pozos de sondeo fueron cruzadas con imágenes satelitales, análisis de suelos e investigaciones subacuáticas. Como resultado, por primera vez, podemos definir con certeza la ubicación y los límites de la ciudad y del pueblo Cueva junto al cual fue construida. La falta de evidencias de origen español, tanto en las investigaciones subacuáticas como en las prospecciones terrestres, reducen la posibilidad de que Bahía La Gloria fuera el antiguo puerto marítimo de la ciudad.

Palabras clave: Santa María de la Antigua del Darién, Tierra Firme, primera ciudad española, prospección arqueológica.

\section{ABSTRACT}

In the year 1510, Santa María de la Antigua del Darién was the first Spanish city founded on American Terra Firma. In 2013, ICANH started a Management and Protection Plan for this site. In the initial phase, the main archaeological objectives were to identify and to delimit the Spanish city area and test the hypothesis that Bahia La Gloria was the city's seaport. Evidence gathered by on-site prospections with test pits were crossed and supported by satellite imagery, soil analyses, and underwater surveys. As a result, for the first time we can define with certainty the city's location and boundaries and those of the Cueva village next to which it was built. Lack of evidence of Spanish origin from underwater surveys and terrestrial prospections, reduce the possibility that Bahia La Gloria was the city's ancient seaport.

Keywords: Santa María de la Antigua del Darién, Terra Firma, first spanish city, archaeological prospection. 
Tenga por aviso y verdad el lector, questa poblaçion de Castilla del Oro es el prinçipio y fundamento de todo lo que en la Tierra-Firme, assi en la costa del Norte como en la del Sur, está descubierto y poblado de chripstianos.

Fernández de Oviedo, Historia general y natural de las Indias, vol. 3, proemio

\section{Introducción}

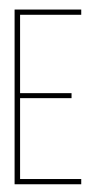

n el año 1510, Santa María de la Antigua del Darién fue la primera ciudad española fundada en la Tierra Firme de América. A pesar de que el asentamiento no duró más de quince años desde la fecha de su fundación, Santa María simboliza el punto de origen (lugar que ocupó durante muchos años en el imaginario de los conquistadores) de una experiencia que, para bien o para mal, iba a representar la transformación de una época que marcaría un antes y un después en la historia. Muchos de los protagonistas más importantes de la ocupación española temprana pasaron por Santa María de la Antigua, incluyendo a Vasco Núñez de Balboa, Francisco Pizarro, Sebastián de Belalcázar, Diego de Almagro, Gonzalo Fernández de Oviedo y Pedrarias Dávila. Allí se realizó lo que se podría definir como un "laboratorio" de la historia posterior de las Américas, en donde se experimentaron modelos contrapuestos de acercamiento y confrontación con las nuevas tierras y sus habitantes (Vignolo y Becerra 2011).

Los estudios arqueológicos de Santa María de la Antigua del Darién han sido esporádicos y no siempre meticulosos debido a su ubicación y a las características ambientales y sociopolíticas del entorno. En particular, en lo que concierne a la ciudad española, los trabajos precedentes más significativos son: la expedición del rey Leopoldo de Bélgica en 1956, de la cual no queda ninguna información científica (Steiner 1991); la expedición de la Universidad Santa María de la Antigua de Panamá en 1966; el trabajo de Graciliano Arcila Vélez (1986) que culminó con la publicación del libro Santa María de la Antigua del Darién, sin duda el estudio más relevante sobre el sitio; y el proyecto de los departamentos de Antropología e Historia de la Facultad de Ciencias Humanas de la Universidad Nacional de Colombia (2006-2008), que estableció una relación de colaboración con los pobladores (Vignolo y Becerra 2011). Pero, a pesar de los importantes 
resultados obtenidos por algunas de estas investigaciones, la ubicación e identificación de la ciudad y sus límites eran aún inciertas.

En el 2013 el Instituto Colombiano de Antropología e Historia (ICANH) y el Ministerio de Cultura emprendieron un proyecto multidisciplinar destinado a crear un Plan Especial de Manejo y Protección de este sitio, que incluyó un componente social, histórico y arqueológico. Este último, que estuvo a mi cargo, tuvo dos objetivos en su fase inicial: primero, identificar y delimitar el área de la ciudad española y, segundo, verificar la consistencia de la hipótesis según la cual Bahía La Gloria y su isla fueron el puerto de la ciudad en el mar Caribe. La primera parte de este artículo presenta los antecedentes históricos de la fundación de Santa María de la Antigua y su ubicación geográfica. La segunda aborda el proceso de investigación en sus aspectos metodológicos y discute los resultados y las interpretaciones en torno de los principales hallazgos.

\section{Las cuatro fundaciones de Santa María de la Antigua del Darién}

La ciudad española de Santa María de la Antigua representa el encuentro de dos mundos o, más bien, el choque estruendoso entre ambos. Fue construida al lado de un poblado indígena llamado Darién, e incluso una parte de ella fue superpuesta sobre este, con una técnica de simbiosis parasitaria ${ }^{1}$ típica de toda la fase inicial de la Conquista. Que el pueblo se llamara Darién lo sabemos indirectamente por los escritos de Gonzalo Fernández de Oviedo, el principal cronista de la fase inicial de la Conquista española y vecino de Santa María de la Antigua: "El río que por alli passa y el pueblo tenían un mismo nombre” (Historia, vol. 2, lib. XXVII, cap. IV). El nombre del río, Darién, lo menciona Fernández de Oviedo en muchas ocasiones (por ejemplo, en Historia, vol. 3, lib. XXIX, cap. VIII). Cuando hablamos de la fundación de Santa María de la Antigua se trata de algo abstracto, pues ¿se puede hablar de un solo acto fundacional? Tal vez la mejor pregunta es: ¿cuántas veces ha sido fundada Santa María de la Antigua del Darién? Con los actuales conocimientos, podemos identificar al menos cuatro momentos fundacionales.

\footnotetext{
1 El parasitismo se refiere a una forma de simbiosis entre dos organismos en la cual solo uno se beneficia de la relación a costa del huésped, por lo cual se considera una forma de depredación.
} 
Primero que todo, sabemos de la presencia de un poblado indígena de habla cueva al momento de la llegada de los españoles. También conocemos la existencia de este poblado desde 1504, cuando una expedición española con fines fundamentalmente esclavistas y de saqueo, al mando del piloto y geógrafo Juan de la Cosa y en la que participó Vasco Núñez de Balboa, llegó por primera vez al lugar:

[...] de allí de Urabá, por lenguas que tomaron de algunos indios que prendieron, se informaron estos christianos de la provincia del Darién, que está cinco o seis leguas frontera de Urabá en la otra costa, donde les dijeron que allí havía mucho oro. É pusieron obra de attravessar y passar allá, y assí lo hicieron, y surgieron donde mejor les pareció, y entraron por el rio arriba del Darién con los bergantines y bateles de las naos una mañana antes que amaneciesse; y dieron en el pueblo de los indios, que estaba cerca del río de la otra parte, y allí tomaron algunos indios y prendieron el cacique, el cual después se les huyó. (Fernández de Oviedo, Historia, vol. 2, lib. XXVII, cap. I)

La segunda fundación es precisamente la que realizan en 1510 Martín Fernández de Enciso y Vasco Núñez de Balboa quienes, a la cabeza de trescientos españoles que huían del desastre de San Sebastián de Urabá ${ }^{2}$, asaltan el poblado de Darién y, luego de derrotar al cacique Cemaco, construyen la primera capilla dedicada a la Virgen de la Antigua. Estos primeros pobladores españoles se asientan en el mismo poblado y construyen sus casas a la manera de los indígenas. Según Fernández de Oviedo, a los cuatro años de la ocupación española del poblado, hay en Darién

[...] quinientos y quince hombres que estaban allí avecindados, y tenían fechas mas de cient casas o buhíos [...]. Había entre aquellos pobladores primeros, mas de mill e quinientos indios e indias naborías que servían a los cristianos en sus haciendas y casas. (Historia, vol. 3, lib. XXIX, cap. VIII)

En 1514 llega Pedro Arias de Ávila, el gobernador nombrado por la Corona de España, comandante en jefe de la flota de alrededor de veinte barcos procedentes de Sevilla con más de 2.000 personas. Él se encarga de transformar

Mediante la capitulación de Burgos en 1508, Fernando el Católico otorga los territorios de Veragua y Nueva Andalucía a Diego de Nicuesa y Alonso de Ojeda, con el título de gobernadores. En octubre de 1510, Alonso de Ojeda funda en la costa oriental del golfo de Urabá el fuerte de San Sebastián, del cual los españoles prácticamente no logran salir, por los continuos ataques de los indígenas urabaes que estaban armados de flechas envenenadas con curare. En poco tiempo se acaban las provisiones y las bajas son muchas, al punto que a los seis meses de su fundación, cuando los españoles deciden abandonar el sitio, de los trescientos hombres llegados con Ojeda no quedan sino unos cincuenta. Estos se encuentran con los refuerzos liderados por Martín Fernández de Enciso y deciden moverse al otro lado del golfo, donde los indios al parecer no utilizan el curare (Mena 2011). 
el primer "pie” español en Tierra Firme de las Indias Occidentales, lo que hasta el momento era solo un fuerte gobernado por Balboa, en una verdadera ciudad dotada, entre otras cosas, de catedral, hospital, monasterios, iglesias, prisión, casa de fundición y casa de contratación. Esta tercera fundación termina alrededor de 1524 cuando la ciudad, casi despoblada, es epicentro de la rebelión de los indígenas encomendados a los últimos habitantes españoles que se habían quedado.

E sus proprios indios deste Diego de Rivero, y otros que con ellos se juntaron, le mataron; y a un hijo suyo, de edad de ocho o diez años, le ahorcaron de la cumbrera de su proprio buhío, y mataron a la madre de aquel niño y otros tres o cuatro cristianos enfermos, y quemaron la mayor parte de aquella ciudad, y entres las otras casas la mía [...]. (Fernández de Oviedo, Historia, vol. 3, lib. XXIX, cap. XXII)

La cuarta y última fundación no tiene más de diez años y es la de los colonos que actualmente viven en la vereda de Santuario, en su mayoría procedentes del departamento de Córdoba, que como veremos a continuación está prácticamente superpuesta sobre el antiguo poblado indígena. El hecho de que hayan transcurrido casi quinientos años entre el abandono de la ciudad de Santa María de la Antigua y la reocupación permanente del lugar hace que las estratigrafías de los niveles de ocupación originales se hayan mantenido relativamente inalteradas (González 2011, 24) ${ }^{3}$. En este largo periodo, la región entera se ha mantenido escasamente poblada y de alguna manera ha estado al margen de la presencia y el control de las instituciones estatales, y representa básicamente un área fronteriza. Como sabemos por las crónicas, Santa María de la Antigua no tuvo tiempo para convertirse en una ciudad de ladrillo o de piedra, pues desapareció tan solo quince años después de su segunda fundación. Las casas fueron construidas principalmente en madera con techos de paja, las viviendas españolas se distinguían de las de los indígenas solo por la presencia de bisagras y clavazón de hierro (Fernández de Oviedo, Sumario, cap. X). Aunque de vida breve, la primera ciudad de América continental ha representado la cuna de las futuras expresiones y contradicciones de la Conquista española de las Américas (Mena 2011), discusión que excede los objetivos de este artículo. Baste decir que en aquel microcosmos que se creó en Santa María de la Antigua podemos leer los indicios de los futuros procesos sociales y políticos que se desarrollarían durante el siglo XVI ${ }^{4}$.

Algunas fuentes sugieren la posibilidad de la existencia de uno de los primeros palenques (refugios de esclavos) en el área de la ciudad después de su abandono, alrededor de 1532 (Inéditos Friede, Documentos, II, doc. 401).

4 Me refiero a las distintas formas en que los españoles se relacionaron con los nativos, mediante la paulatina construcción de un sistema que se fija desde finales del siglo XVI y que 


\section{Ubicación}

El área del golfo de Urabá se encuentra en la costa noroeste de Colombia, sobre el mar Caribe. La región se caracteriza por altitudes contrastantes que varían entre las costas y las zonas montañosas constituidas por ramificaciones de la cordillera Occidental de los Andes (figura 1).

El sitio de Santa María de la Antigua del Darién, en el municipio de Unguía, departamento del Chocó, está situado dentro de un sistema de colinas al oeste de la cuenca aluvial del río Atrato y al este y sureste de la serranía del Darién, a una altura entre 20 y $35 \mathrm{~m}$ s. n. m. El curso del río Tanela (el antiguo Darién) actualmente pasa a una distancia de entre 300 y $500 \mathrm{~m}$ al oeste de la zona arqueológica. En esta hay una pequeña vereda constituida por unas 20 casas llamada Santuario. El poblado más grande y más cercano es Tanela, a unos $2 \mathrm{~km}$.

\section{Estrategia social y estrategia arqueológica}

El área de investigación es y ha sido especialmente afectada desde hace unas décadas por fenómenos, por lo general violentos, entre facciones políticas opuestas que, entre otras cosas, han generado el surgimiento de nuevos latifundios, en su mayoría controlados por grupos paramilitares que operan en el borde de la legalidad. Hubiera sido imposible proponer una metodología para la prospección arqueológica del sitio, así como para investigaciones futuras, desentendida de la situación sociopolítica de la zona. Este trabajo es el resultado de la confluencia de esfuerzos que tienen expectativas diferentes, entre estas, la necesidad de hacer una prospección arqueológica de alta calidad que genere un producto científico y trabajar con un enfoque social a fin de crear las condiciones sociales necesarias para que el patrimonio arqueológico e histórico pueda ser incorporado en las dinámicas cotidianas de las poblaciones locales (colonos campesinos, indígenas emberás y cunas, comunidades afrocolombianas), con la convicción de que el territorio, la historia y la gente forman parte del mismo patrimonio.

tiene como base la institución de la encomienda en las primeras fases de la Conquista. Este fue un proceso en continua transformación, que vio la formulación de varias leyes sobre el tema: la Real Provisión de 1503, las Leyes de Burgos de 1512 y su ampliación en 1519, la Ley de 1527 y, finalmente, las Leyes Nuevas de 1542 que abolieron las encomiendas (y llevaron a la guerra civil en Perú, entre otras cosas). El proceso terminó, en el último cuarto del siglo XVI, con una desobediencia de facto a la ley. 


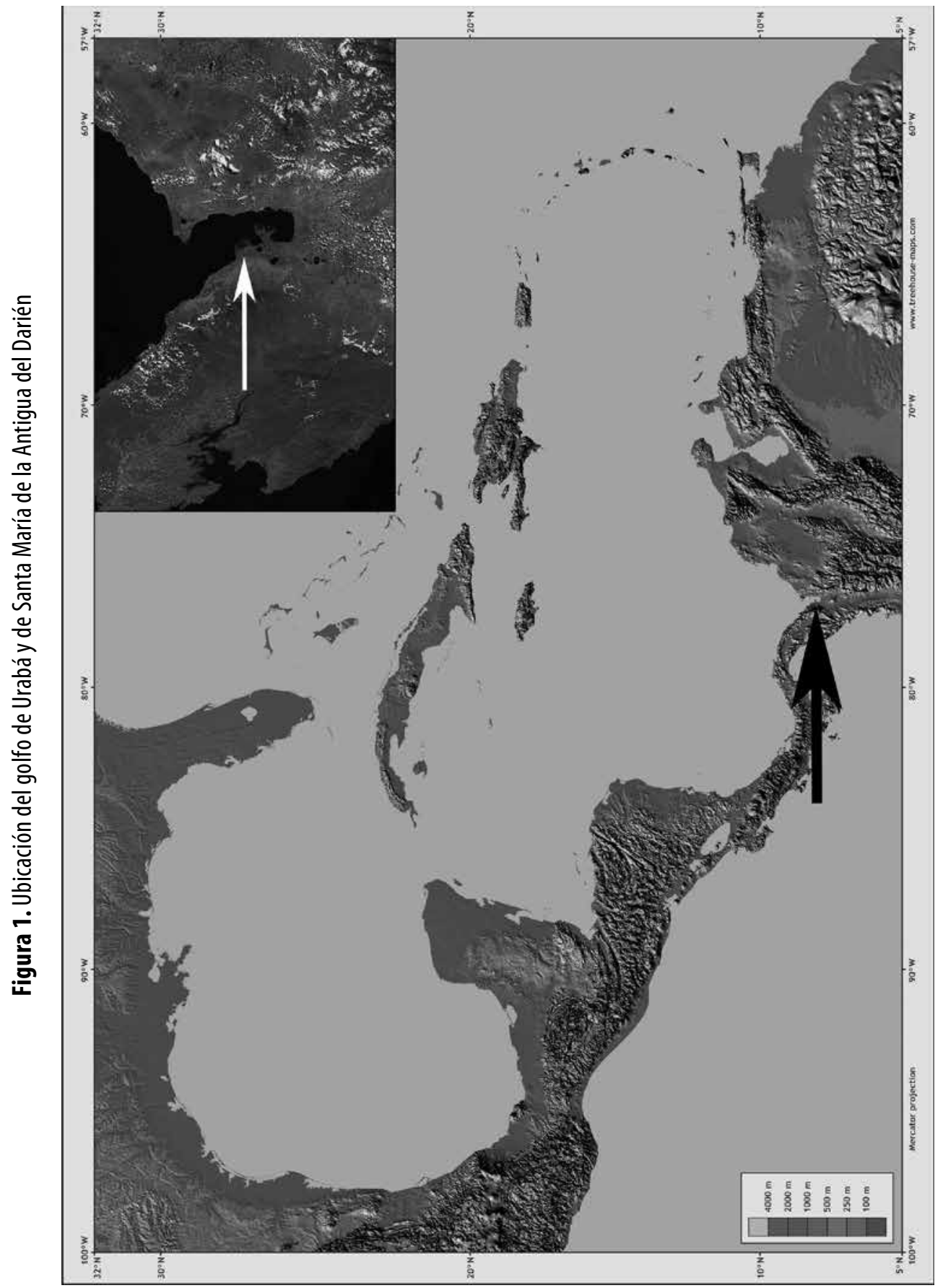

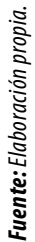


La metodología ha tenido en cuenta esta perspectiva y ha construido una estrategia de relación continua con la comunidad local, en la que tanto la ejecución de las diversas actividades como el proceso de reconocimiento y de interpretación de los datos arqueológicos recogidos se llevaron a cabo con la participación de los habitantes de la zona. La organización del grupo de trabajo fue parte de un proceso de socialización desarrollado en los meses anteriores al estudio arqueológico en campo. A raíz de lo concertado en las reuniones con las comunidades y organizaciones presentes en el territorio (la comunidad campesina de colonos de Santuario y Tanela; las comunidades indígenas emberá, katío y cuna, de los poblados de Citará, Arquía y Cuti; la comunidad afrocolombiana de Tarena y el Consejo Comunitario Mayor del Bajo Atrato), se decidió que miembros de cada uno de estos grupos hiciera parte de la fuerza de trabajo del proyecto. Gracias a este método de investigación, basado en la participación directa de la comunidad local, ha sido posible obtener resultados positivos y estimulantes tanto a nivel arqueológico como socioambiental.

En esta etapa inicial se emplearon metodologías distintas y complementarias con el fin de lograr los objetivos principales de este trabajo: una investigación sociológica preliminar en el año 2013, para familiarizar al equipo con las dinámicas sociales locales que fueron tenidas en cuenta durante la planificación y ejecución de la misión arqueológica. Para hacer un reconocimiento aéreo del terreno, también se adquirieron imágenes satelitales en alta definición, que fueron estudiadas e interpretadas por un equipo de investigadores especializados en el reconocimiento de vestigios arqueológicos. El trabajo arqueológico de campo se llevó a cabo mediante la excavación a mano de 891 pozos de sondeo, cada uno de $1 \mathrm{~m}$ de profundidad con un diámetro de $80 \mathrm{~cm}$, una superficie de aproximadamente $8 \mathrm{~km}^{2}$, y un estudio estratigráfico detallado en algunos pozos de sondeo particularmente significativos, de los cuales se recogieron muestras de suelo que se sometieron a análisis granulométrico y químico. Por otra parte, un equipo de arqueólogos subacuáticos se ha ocupado de registrar la presencia de objetos españoles en las zonas internas y externas de Bahía La Gloria mediante métodos de prospección directos (autópticos, por medio de inmersiones subacuáticas) e indirectos (a través del uso de un magnetómetro). La totalidad de la información arqueológica recogida, obtenida a través del estudio comparativo de las intervenciones descritas, fue traducida e integrada en una cartografía temática digital, en un entorno SIG. 
En resumen, se utilizó una metodología multidisciplinaria con eje en una prospección arqueológica de campo sistemática, apoyada y reforzada con el uso de técnicas procedentes de disciplinas complementarias. Los resultados de esta prospección se cruzaron con los de los estudios realizados sobre las imágenes satelitales y los análisis de suelos. Es importante aclarar que esta fase preliminar tuvo como objetivo identificar áreas de densidad de material arqueológico, ya que se basa principalmente en un estudio estadístico y no tiene en cuenta en forma detallada la estratigrafía general.

\section{Encontrar y delimitar una ciudad colonial y su puerto}

El terreno del área de las prospecciones se utiliza predominantemente para la ganadería, pero también hay abundantes cultivos de plátano y árboles maderables (especialmente teca), unos cuantos sembrados de arroz y cacao de pequeña extensión, zonas boscosas, cuerpos de agua y zonas pantanosas. Por estas condiciones se eligió una metodología de prospección por pozos de sondeo (Ammerman 1981, 81; Cambi y Terrenato 1994, 127), los cuales se realizaron de forma manual (0,8 x 0,8 $\mathrm{m}$ de ancho, $1 \mathrm{~m}$ de profundidad, divididos en tres niveles de profundidad de unos $33 \mathrm{~cm}$ cada uno) y a una distancia de $50 \mathrm{~m}$ de pozo a pozo, dada la imposibilidad de recurrir a medios mecánicos. Debido a la complejidad del terreno, caracterizado por la presencia de vegetación tropical, canales de irrigación y divisiones continuas con alambrados, no fue posible llevar a cabo una prospección con malla ancha. Después de tres semanas, la fase más importante del trabajo de prospección se completó con la realización de 827 pozos de sondeo en la zona principal de la investigación, correspondiente a un área de aproximadamente $6 \mathrm{~km}^{2}$ alrededor de la vereda de Santuario.

En las semanas siguientes se hizo una verificación de los primeros datos obtenidos con el análisis de las imágenes satelitales y el estudio de suelos. Durante estas dos actividades se abrieron 13 pozos de sondeo adicionales, siempre en la zona principal. Las prospecciones en la zona costera de Bahía La Gloria y Tarena se llevaron a cabo durante una semana, exactamente con la misma metodología aplicada en la zona principal, y se hicieron otros 51 pozos de sondeo. 


\section{Resultados e interpretaciones}

\section{La prospección por pozos de sondeo en la zona principal: Darién y Santa María de la Antigua}

La zona principal cubre aproximadamente $6 \mathrm{~km}^{2}$. Incluye los alrededores del pequeño poblado de Santuario y bordea las áreas de la iglesia de Santa María de la Antigua $^{5}$, Tanela Viejo, el cementerio actual, la finca La Francia, la finca Hoyos, la finca Villegas y un cuadrante al oeste del río Tanela (figura 2).

Se eligió como centro de la zona principal la iglesia contemporánea de Santa María de la Antigua, donde la tradición oral local siempre ha ubicado el centro de la ciudad española.

Los resultados de las prospecciones (figura 3) están representados gráficamente con círculos blancos y negros que muestran la densidad de los hallazgos, de acuerdo con la cantidad de fragmentos/artefactos cerámicos encontrados por cada pozo de sondeo. Los pozos de sondeo negativos (que carecen de material arqueológico) están indicados como triángulos negros.

En esta ilustración podemos observar claramente dos amplias áreas principales con una gran densidad de material, una al sureste de la iglesia católica (1) y la otra coincidente en parte con la zona habitada de Santuario (2). Además de estas dos grandes áreas bien definidas, se pueden observar otros sitios más pequeños, con densidad variable de hallazgos cerámicos, de los cuales hablaremos luego.

En la figura 3, el material arqueológico indígena se representa con círculos blancos y está presente con un alto grado de densidad en todas las áreas en que las prospecciones dieron resultado positivo. El material español se identifica con círculos negros y parece estar concentrado en un área bien definida, inmediatamente al sureste de la actual iglesia de Santa María de la Antigua (1). Hay también una presencia esporádica pero significativa de material español al noroeste de este primer sitio, en una zona que corresponde a la actual vereda de Santuario (2).

La notable diferencia cuantitativa entre los materiales españoles e indígenas (el número mínimo y máximo de fragmentos/artefactos encontrados por pozo de sondeo oscila entre 1 y 100 unidades atribuibles a la cultura española y entre 1 y 521 para la cultura indígena) es un claro reflejo, por una parte, de las

$5 \quad$ Fundada en 1992 con ocasión del quinto centenario del descubrimiento de América, por la diócesis de Apartadó, en honor de la primera sede episcopal del continente americano. 


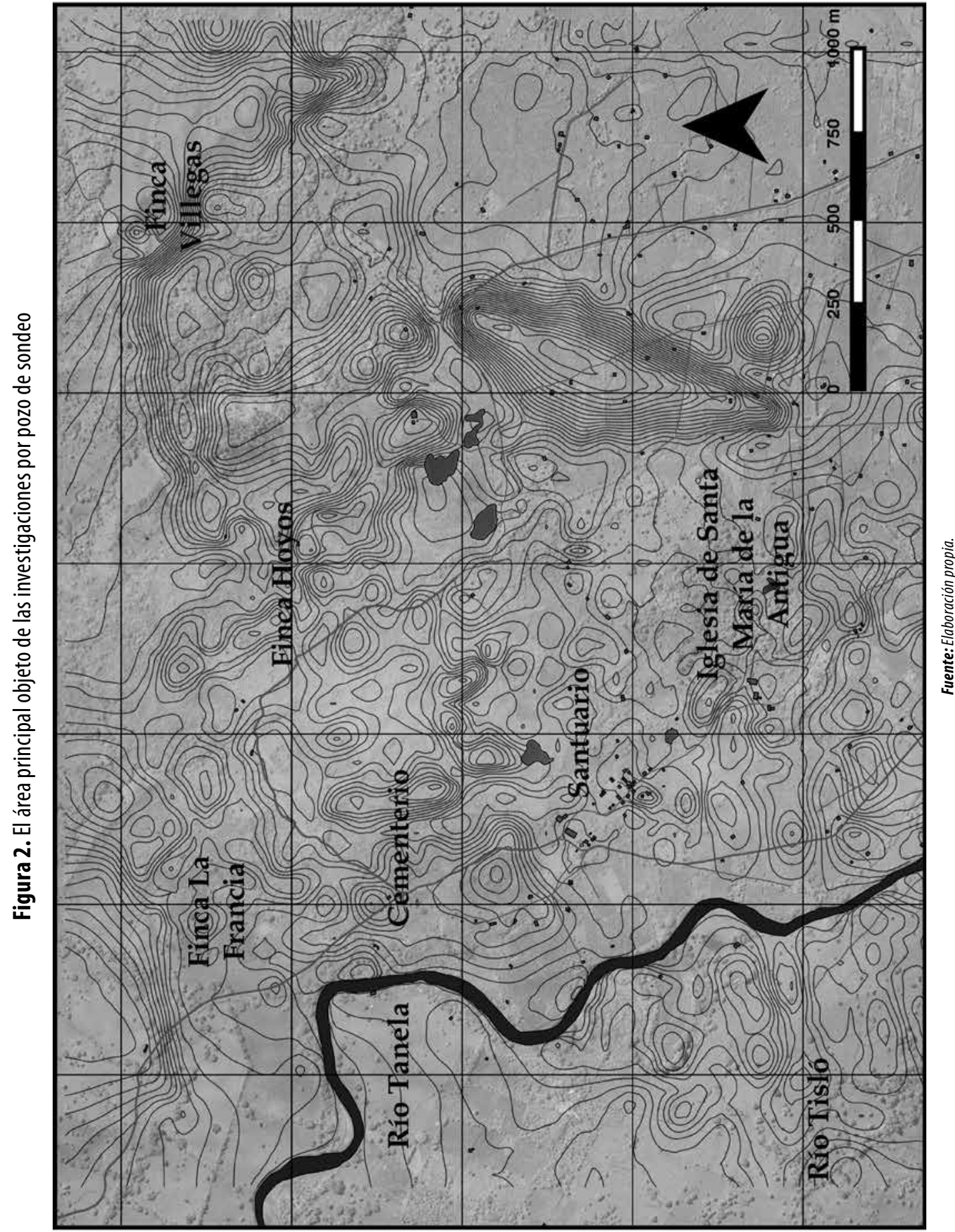




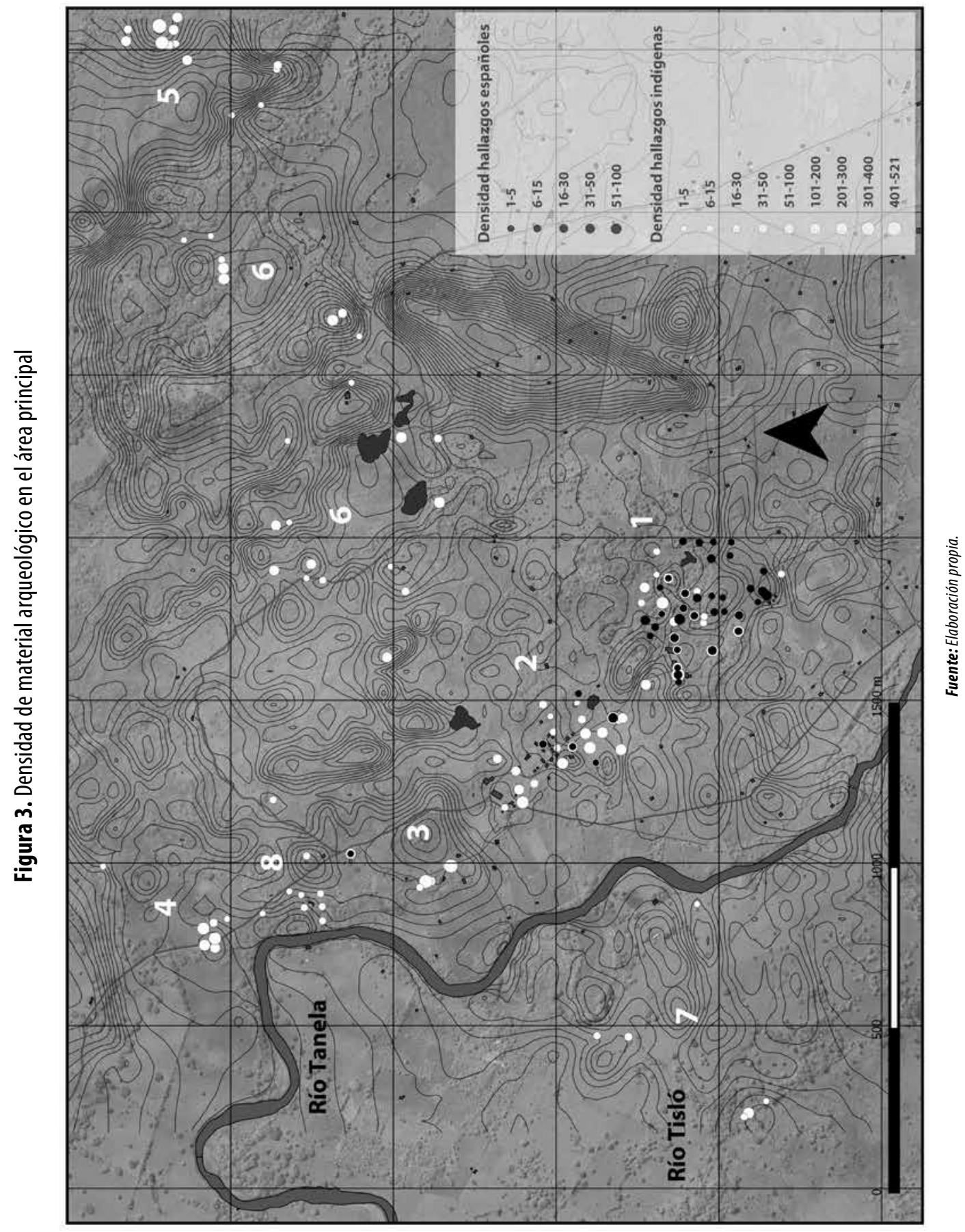


diferencias en el tiempo de permanencia de las dos culturas en el área objeto de estudio y, por otra, de la evidente presencia de artículos cerámicos de fabricación local en las mesas y las cocinas de los españoles. Esta observación resulta evidente en la figura 4, donde se sobreponen los hallazgos españoles (en negro) e indígenas (en blanco) en las dos áreas con mayor densidad de hallazgos.

Las dos tradiciones cerámicas están presentes en el área con mayor densidad española ( $21,1 \%$ de cerámica europea; $78,9 \%$ de cerámica indígena). En el área con mayor densidad indígena también hay un porcentaje significativo de material español (3,5\%). El material cerámico y metálico encontrado es compatible y contemporáneo a la fundación de Santa María de la Antigua del Darién. Incluso las dimensiones del área con prevalencia de material español son compatibles con las de una ciudad colonial de la época. Tomando en consideración la ciudad de Panamá, fundada en 1519 por el mismo Pedrarias que fundó Santa María de la Antigua en 1514, y haciendo una comparación con el famoso mapa de Roda $^{6}$ de 1609 (cuando Panamá tenía alrededor de 5.000 habitantes), el área con alta concentración de material español es de 20 ha, el área con alta concentración de material indígena abarca 13 ha y el área correspondiente a Panamá mide alrededor de 25 ha.

Por todo lo anterior, el principal resultado de las investigaciones por pozos de sondeo resulta ser la efectiva detección de la ciudad de Santa María de la Antigua del Darién. El dato sobresaliente es su división en dos partes "étnicamente" distintas, la primera de las cuales correspondería al pueblo Cueva de Darién, en el que se establecería la expedición al mando de Balboa y Fernández de Enciso después de la victoria sobre los nativos en 1510, y la segunda sería la ciudad fundada por Pedrarias Dávila en 1514. De acuerdo con Fernández de Oviedo, los casi 300 hombres que cayeron sobre el pueblo de Darién, procedentes del desastre de San Sebastián de Urabá, eran baquianos, o veteranos de las Indias Occidentales y casi todos residentes en La Española (Fernández de Oviedo, Historia, vol. 3, lib. XXIX); muy difícilmente habrían llevado consigo cerámica europea. En cambio, la expedición organizada por la Corona española en 1514 fue concebida como un verdadero acto de colonización de las nuevas tierras de ultramar; los más de 2.000 colonos, casi todos españoles, llevaron todo lo necesario para la fundación de una ciudad ibérica. Esta es la razón que explica las diferencias en la densidad de material de origen europeo en las dos áreas que hemos nombrado como sitios arqueológicos: Darién y Santa María de la Antigua.

6 Cristóbal de Roda Antonelli fue un ingeniero militar italiano que se encargó del diseño y la realización de varias fortificaciones de defensa en las Indias Occidentales. En 1609 realizó un plano detallado de la ciudad de Panamá con el fin de planear sus fortificaciones. 


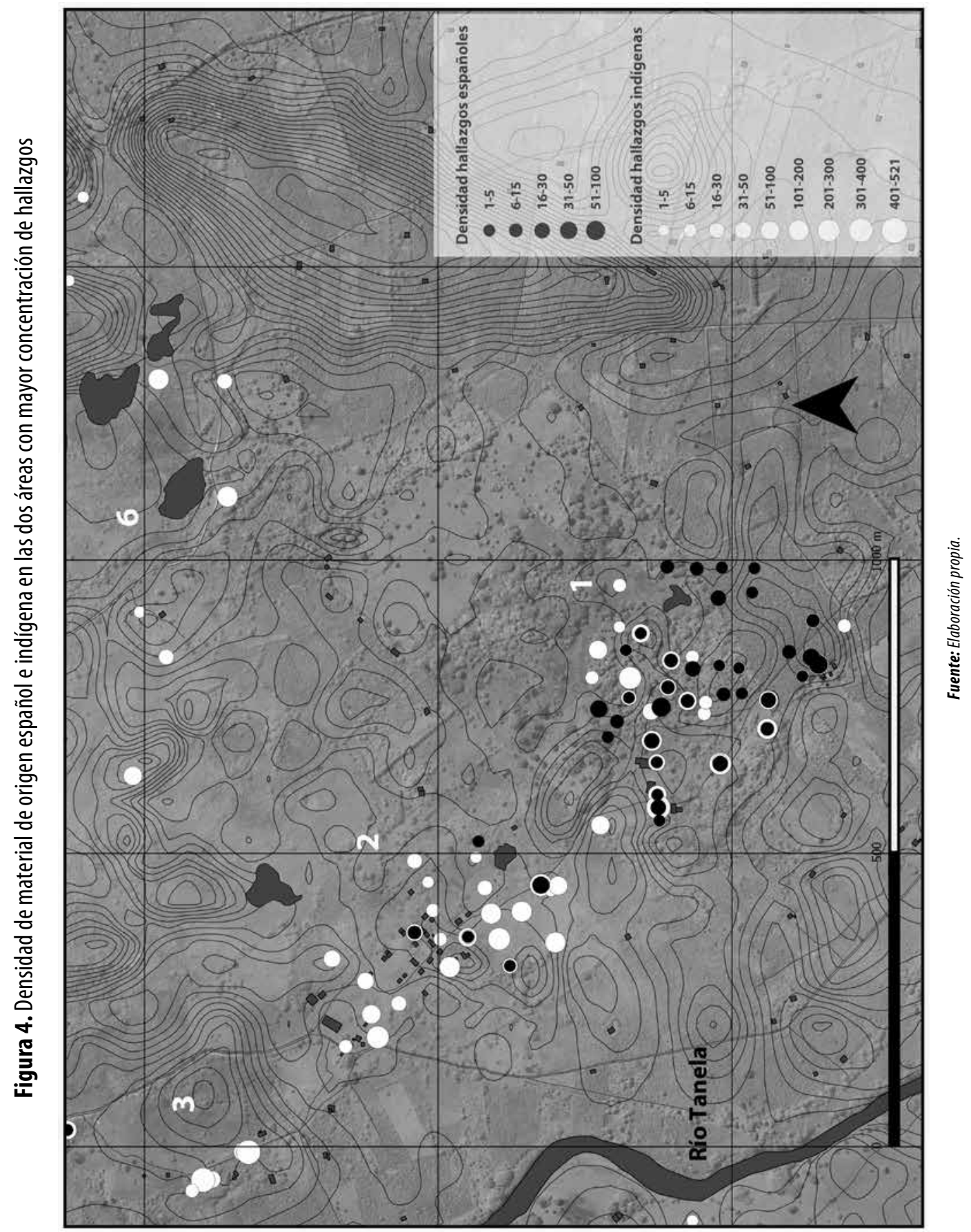


Resulta evidente de la lectura de las crónicas de la época que el segundo asentamiento nunca habría podido sostenerse sin la existencia del primero y de sus habitantes (así como de una red de otros pueblos de la región). Santa María de la Antigua/Darién debió de ser una sola entidad con intercambios continuos, en el periodo entre 1514 y alrededor de 1524, cuando la ciudad fue abandonada.

El área del Darién tiene dimensiones considerables (13 ha), lo que atestigua la importancia de este poblado y su probable crecimiento después de la llegada de los españoles en 1510. Como hemos visto, según las palabras de Fernández de Oviedo, al arribo de la armada de Pedrarias en junio de 1514 vivían en el Darién más de 500 españoles y más de 1.500 indígenas "que servían a los cristianos en sus haciendas y casas” (Fernández de Oviedo, Historia, vol. 3, lib. XXIX, cap. VIII). La mayoría de los artículos de cerámica y de los otros artefactos de origen ibérico llegaron con la expedición de Pedrarias, por lo que podemos suponer que el grupo que ocupaba y vivía en el poblado de Darién entre 1510 y 1514 utilizó las técnicas locales de construcción indígena y cerámica de producción local.

Podemos hacernos una idea de la estratigrafía presente en el Darién observando las paredes de los pozos de sondeo en su zona central. La estratigrafía del periodo del contacto empieza justo debajo del nivel del suelo y tiene un espesor de unos 10-15 cm. A este estrato le sigue un consistente estrato marrón oscuro de 20-30 cm, que evidencia una actividad antrópica bastante duradera. La capa inferior, de arcilla compacta de color amarillo oscuro, aparentemente estéril, a veces es cortada y rellenada por actividades de tipo antrópico (huecos, hornos de tierra, cortes, etc.). De todos modos es necesario contar con futuras excavaciones estratigráficas extensivas para confirmar estos datos.

Volviendo a la figura 3, con los resultados de las prospecciones podemos distinguir claramente otros sitios arqueológicos prehispánicos en el territorio alrededor de la que hemos identificado como la ciudad de Santa María de la Antigua del Darién (1 y 2):

1. La zona alrededor del actual cementerio es un sitio con alta concentración de materiales que, por su cercanía geográfica y la tipología del material cerámico, suponemos que se relaciona con el sitio arqueológico del Darién (3).

2. La zona bastante amplia del viejo poblado de Tanela Viejo, aunque con una baja concentración cerámica por pozo de sondeo (4).

3. La zona de Las Minas, en el terreno de la finca La Francia, probablemente fue un asentamiento por su alta concentración cerámica y por sus dimensiones (5). 
4. Una vasta área en el terreno de la finca Hoyos en la cual los hallazgos han sido más dispersos, testimonio de pequeños núcleos habitacionales diseminados en las alturas de la zona (6). En esta área podemos reconocer cinco sitios prehispánicos diferentes, de pequeñas dimensiones.

5. La zona de Muribá, en el terreno de la finca Villegas, con altísima concentración de material, casi seguramente correspondiente con un asentamiento prehispánico (7). Al suroeste de esta área hay evidencias de un segundo sitio prehispánico con menor densidad cerámica.

6. La zona alrededor del río Tisló, al lado occidental del Tanela, donde se encontró una capa de origen antrópico a unos $94 \mathrm{~cm}$ de profundidad, de unos $40 \mathrm{~cm}$ de espesor. En el resto de la zona al oeste del río Tanela, las prospecciones han dado escasos resultados, probablemente a causa de los altos niveles de suelo de origen aluvial relativamente recientes.

\section{Los materiales}

En este apartado haremos una breve referencia a los materiales encontrados, ya que su estudio, en especial en lo relativo a la cerámica indígena, se encuentra todavía en curso. Como hemos visto, el material de origen español se halla principalmente en la zona que hemos reconocido como la parte de la ciudad fundada por Pedrarias Dávila en 1514 y a la que hemos denominado Santa María de la Antigua, para diferenciarla del pueblo indígena preexistente de Darién, donde Balboa y Enciso habían formado la primera colonia. Es preciso recordar que la presencia española en el área no duró más que un quinquenio y que la cerámica y la mayoría de materiales de origen europeo solo llegaron con la expedición de Pedrarias, lo que reduce el tiempo de permanencia de estos artefactos en el área a poco más de diez años.

En el área de Santa María de la Antigua, los fragmentos cerámicos de origen europeo son el 21,1\% del total y en el área de Darién son el 3,5\%. Estos pertenecen a estilos cerámicos cronológicamente compatibles con el tiempo de vida de Santa María de la Antigua (Avery 1997; Deagan 1987; Fairbanks 1966, 1972; Goggin 1960, 1968; Lister 1987).

1. Cerámica de barro temprana: roja (1500-1750), feldespato incluido o empedrada (1500-1600), bizcocho (1500-1550).

2. Botijas: olive jar early style (1500-1570).

3. Vidriados: green bacin/green lebrillo (1490-1600), vidriado verde (14901600), melado (1490-1550). 
4. Mayólicas: Columbia liso (1490-1650), Columbia green dipped (14901564), yayal azul sobre blanco (1490-1625), Isabela policromo (14901580), Caparra azul (1492-1600).

En el transcurso de las investigaciones, en una zona específica de Santa María de la Antigua, se han encontrado algunos ejemplares de azulejos españoles de tradición mozárabe, probablemente relacionados con la decoración parietal de un edificio principal. En particular, los azulejos encontrados aquí son de arista o cuenca, producidos típicamente en Sevilla y Toledo, que corresponden estilísticamente con el cuenca tile-type A (en FLMNH, Historical Archaeology, fechado entre 1500-1575), con motivos geométricos de bandas entrelazadas o motivos florales estilizados, en las que los colores predominantes son el naranja oscuro, el blanco, el azul y el negro-pardo. Se ha hallado también otro tipo de azulejo de arista ya documentado en la excavación de Graciliano Arcila (1986), que se caracteriza por una preparación en relieve marcado y una decoración con motivos azules en fondo blanco (figura 5).

Figura 5. Azulejos procedentes del pozo de sondeo D38 y de prospección superficial en el sector del tecal

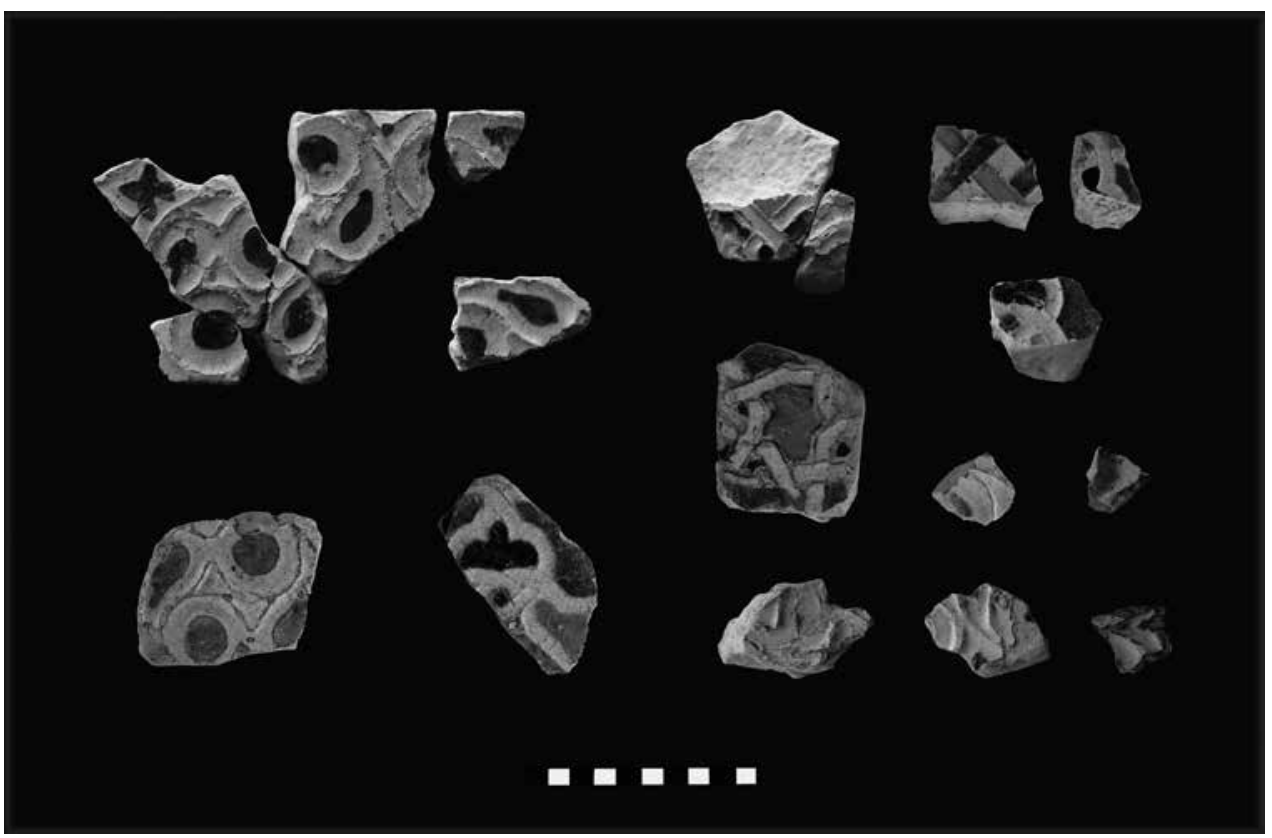

Fuente: Elaboración propia. 
En el sector del tecal, correspondiente a la parte meridional del área de Santa María de la Antigua, se encontraron abundantes fragmentos de ladrillo de origen español. Por ahora podemos distinguir tres tipologías, de color y consistencia distintos: amarillo, de consistencia más tizosa; rojo, de consistencia compacta; morado, con fuerte presencia de inclusos arenosos. El único ejemplar del cual tenemos el largo completo es uno morado que mide 29,7 x 13,2 x 4,5 cm. En general, los espesores están entre los 4,25 y los 5,55 cm y el ancho varía entre 11,0 y $13,2 \mathrm{~cm}$.

El hallazgo de clavos de origen español ha sido muy abundante y presenta una gran variedad de tamaños. En particular, se aprecian tamaños de entre 3 y 20,5 cm con diámetros de cabeza de 1,2 a 4,1 cm. La sección de todos los clavos es rectangular, entre 4 y $15 \mathrm{~mm}$. Las cabezas son convexas o planas, de formas redondeadas-irregulares, semirrectangulares, cuadrangulares, cuadrangularesirregulares, semipentagonales y semihexagonales. Los espesores de las cabezas varían entre los 2 y los $10 \mathrm{~mm}$. Estas diferencias se deben al tipo de utilidad de los clavos: los más gruesos y con cabeza más espesa son los típicos de construcción; los más pequeños con cabeza más sutil son aquellos utilizados como decoración.

También se encontraron otros objetos metálicos, entre los cuales se destacan un machete/daga, dos balas de falconete, una de arcabuz y el pomo de la empuñadura de una espada (figura 6). El machete/daga, hallado en el área del Darién, es de hierro y tiene $42 \mathrm{~cm}$ de largo, con un calibre de hasta 0,7 cm en su parte más ancha. Aún es visible la parte metálica de la empuñadura y en general se conserva bien su forma original. La parte más ancha es de 6,5 cm y uno de los bordes es recto y otro de corte (figura 6 , n. ${ }^{\circ}$ ). Las balas de falconete son de plomo con núcleo de hierro y se encuentran bien conservadas. La primera nunca se disparó y está intacta, con un diámetro (calibre) de 6,5 cm; la segunda fue disparada y presenta la huella del cubo de hierro que formaba originalmente su núcleo. La bala de arcabuz, intacta, es muy pequeña y tiene un diámetro (calibre) de $1 \mathrm{~cm}$ (figura 6, n. ${ }^{0} 1$ ). El pomo de la empuñadura de espada tiene un diámetro de $5 \mathrm{~cm}$ y una altura de $6 \mathrm{~cm}$ que remata en una lámina doble de $3 \mathrm{~cm}$ de largo (figura 6, n. ${ }^{\circ}$ ).

En cuanto al material indígena, actualmente no existe ningún estudio sistemático de la cerámica prehispánica de la zona y por lo tanto no contamos con tipologías de referencia. Los trabajos arqueológicos en contextos prehispánicos más cercanos geográficamente se realizaron en El Estorbo, al lado oriental del golfo de Urabá (Santos 1982), en Capurganá (Bedoya y Naranjo 1985), en La Gloria (Correal y Pinto 1983), además de la obra de Graciliano Arcila en Santa María de la Antigua (1986). Infortunadamente, los trabajos más detallados sobre los materiales son los más distantes geográficamente (El Estorbo y Capurganá). 
Figura 6. Objetos metálicos procedentes de las prospecciones

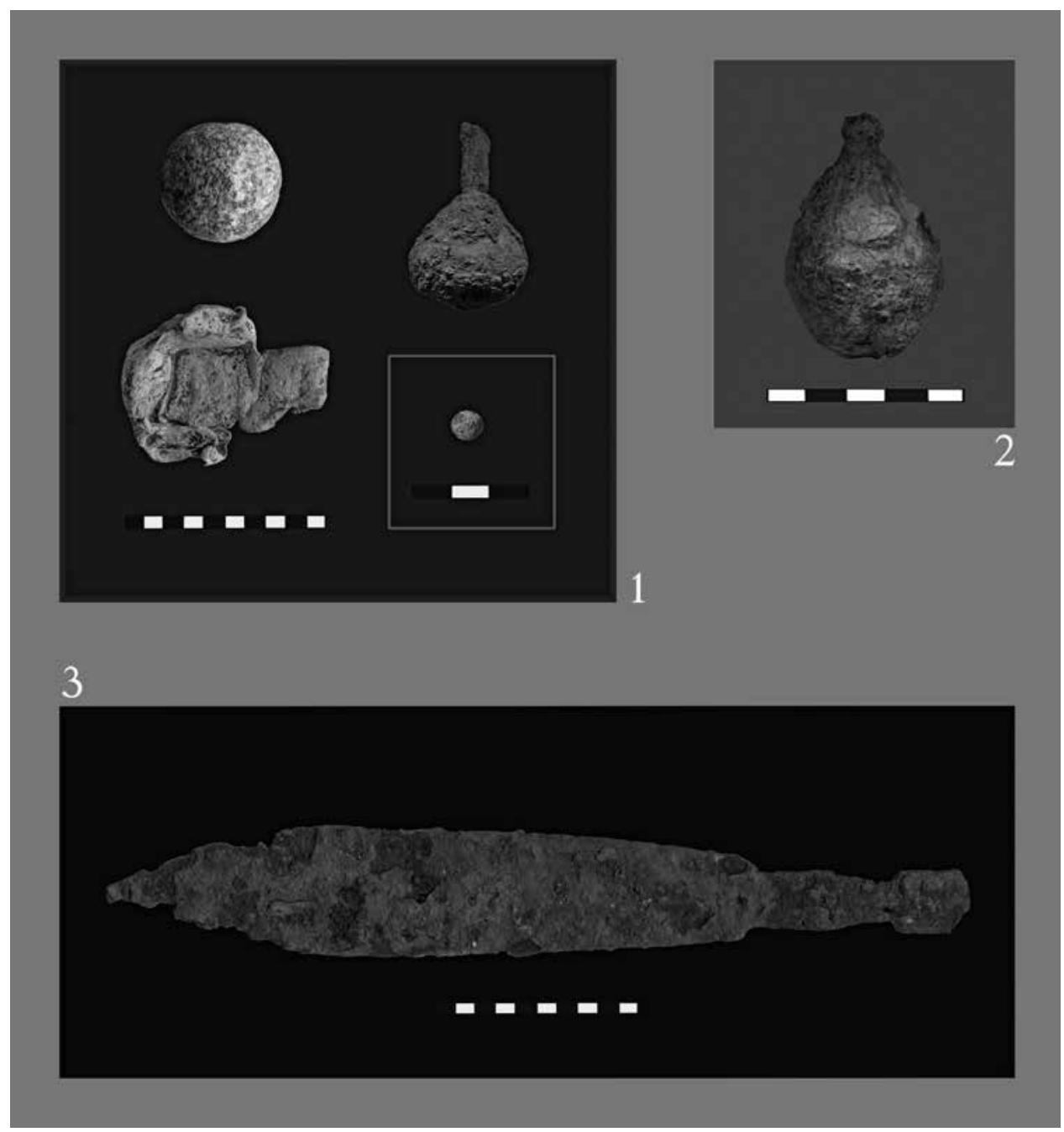

Fuente: Elaboración propia.

La existencia de la ciudad española de Santa María de la Antigua del Darién fue breve y estuvo enmarcada en un espacio cronológico muy bien definido (1510-1524). Su estratigrafía ha permanecido sellada en el tiempo ya que no hubo asentamientos posteriores. Esto significa que el material encontrado en las estratigrafías del periodo de "contacto" pertenece a un marco cronológico muy corto en términos arqueológicos, que podrá ayudar a perfeccionar las cronologías de tipologías de material europeo existentes. Al mismo tiempo, es una base 
muy precisa para la realización de tipologías cerámicas indígenas que, como hemos visto, en el momento no existen para la región. El estudio sistemático de la cerámica prehispánica de la región de Santa María de la Antigua y la creación de una tipología basada en referencias cronológicas derivadas de excavaciones estratigráficas son objetivos específicos de este proyecto. En esta fase inicial solo nos remitimos a nuestras tablas que ilustran algunos fragmentos cerámicos y formas asociadas (figura 7).

\section{Resultados e interpretaciones. La prospección por pozos de sondeo en la zona costera}

El segundo punto clave de las prospecciones del 2013 consistía en averiguar si Bahía La Gloria y su isla constituyeron el puerto en el mar Caribe de Santa María de la Antigua del Darién, como relata la tradición oral de la región. Las fuentes, de hecho, refieren la existencia de un puerto en el Atlántico. Fernández de Oviedo habla de un surgidero (Historia, vol. 3, lib. XXIX, cap. VII), es decir, una extensión de agua adecuada para el anclaje y, por lo tanto, no un verdadero puerto. Fue probablemente en ese sitio donde los españoles construyeron una suerte de almacén, llamado toldo, en el que se guardaban las provisiones y mercancías antes de llevarlas (y venderlas muy caras) a la Casa de Contratación de Santa María. Este habría sido el mismo toldo quemado sucesivamente como consecuencia directa de la codiciosa política de los administradores de la ciudad (Fernández de Oviedo, Historia, vol. 3, lib. XXIX, cap. IX). En los años posteriores al abandono de la ciudad, que tuvo lugar alrededor de 1524-1525, este puerto siguió siendo utilizado esporádicamente, como sucedió en 1532 (Friede, 1955-1960, II, doc. 401).

Como hemos señalado, en la tradición oral de los habitantes del área, el sistema formado por la playa de Bahía La Gloria, su isla principal y el muelle bajo el agua o rompeolas, que conecta a los dos, correspondería al puerto de la ciudad española. Esta hipótesis tenía más fuerza debido al recuerdo de dos cañones españoles presentes hace un tiempo en la isla y de los cuales ya no hay evidencia. El muelle es una especie de camino-terraplén subacuático de aproximadamente $2 \mathrm{~m}$ de ancho en su punto máximo y $340 \mathrm{~m}$ de largo, formado al parecer por piedras similares a las que constituyen la superficie de la isla. En ciertas épocas del año, este camino incluso emerge por encima de la superficie del agua. 
Figura 7. Cuencos y vasijas subglobulares de tradición indígena procedente de las prospecciones

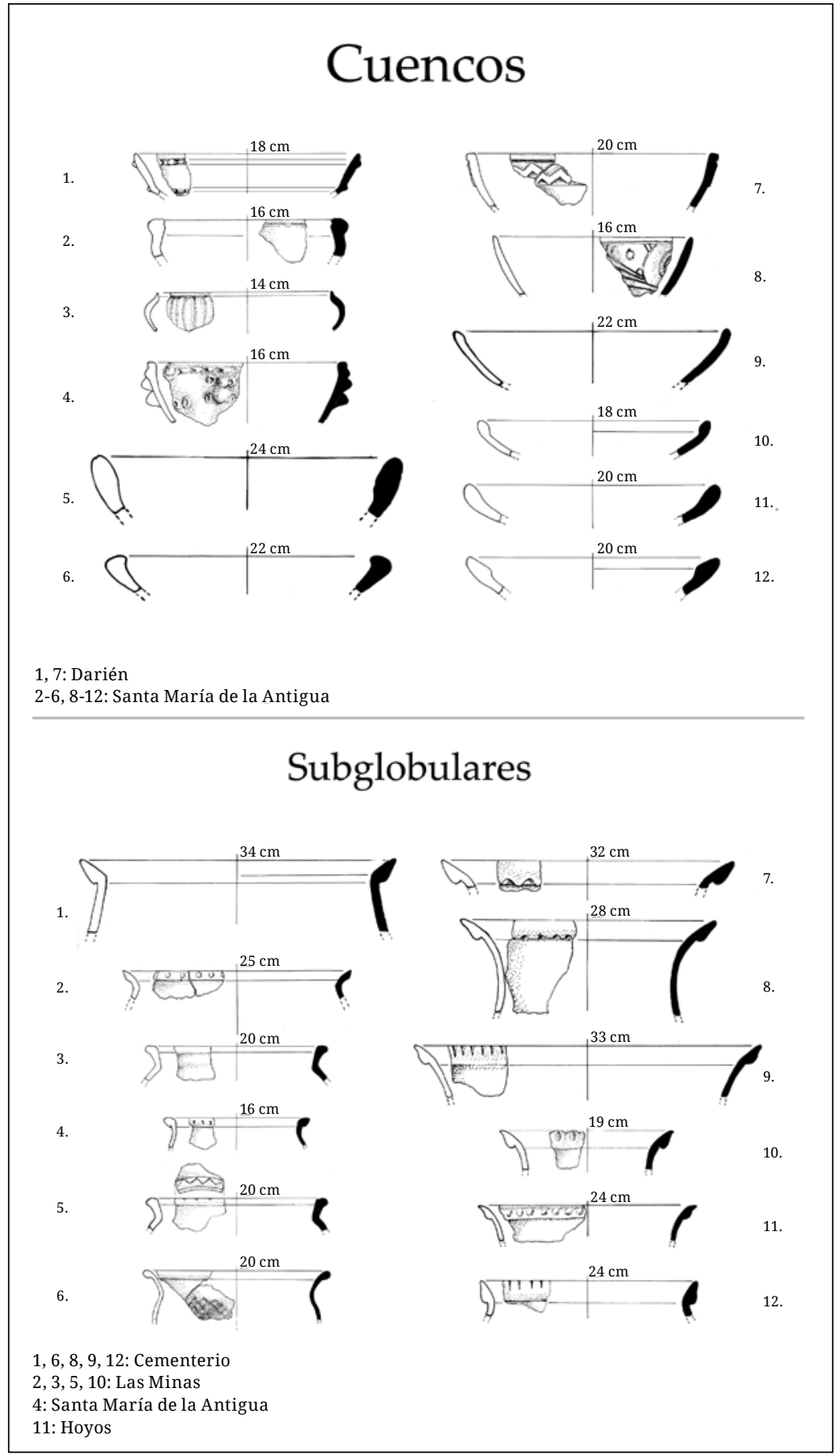

Fuente: Elaboración propia. 
Para comprobar esta hipótesis, se organizó una prospección con magnetómetro y con inmersiones en la bahía, dirigida por el profesor Juan Guillermo Martín de la Universidad del Norte de Barranquilla. Adicionalmente, se realizaron prospecciones por pozos de sondeo a lo largo de la costa de Bahía La Gloria al pueblo de Tarena (figura 8). La prospección con magnetómetro e inmersiones no ha producido ningún tipo de resultado que pueda estar relacionado con el hallazgo de material de origen español (Martín 2015). En las prospecciones terrestres se hicieron 51 pozos de sondeo a lo largo de la costa, que produjeron evidencia de dos asentamientos prehispánicos importantes en Bahía La Gloria y Tarena (figura 8).

A pesar de la gran cantidad de material cerámico encontrado, todavía en estudio, no se ha hallado un solo objeto de origen español. Todo el material antrópico encontrado en el curso de las prospecciones costeras es de origen prehispánico. Este hecho, combinado con los resultados de la prospección submarina, pone en duda la hipótesis inicial que planteaba a Bahía La Gloria como puerto de Santa María de la Antigua del Darién. Es muy poco probable que un puerto que recibiera embarcaciones procedentes de viajes transoceánicos no presente ningún rastro de reparaciones realizadas en los buques. Además, las fuentes citan muchas veces la construcción de barcos en este mismo puerto (p. ej. Fernández de Oviedo, Historia, vol. 3, lib. XXIX, cap. XV). Estas actividades dejarían necesariamente trazas evidentes. A pesar de otros puntos de vista (Correal y Pinto 1983), el autor de este trabajo encuentra difícil un origen no antrópico para el muelle, que sigue siendo, por el momento, una evidencia muy interesante y estimulante para ser estudiada en indagaciones futuras.

\section{Interpretación de las informaciones satelitales}

En el ámbito del proyecto Santa María de la Antigua del Darién, que entre sus objetivos tenía el reconocimiento y la delimitación de los sitios arqueológicos en una vasta área carente de una cartografía detallada y actualizada, la adquisición y el estudio de imágenes satelitales en alta resolución eran una prioridad. Estas imágenes fueron introducidas en un ambiente GIS para el posicionamiento y procesamiento de los datos adquiridos en el transcurso de las prospecciones. Las imágenes pancromáticas y multiespectrales capturadas por los satélites World View 1, World View 2 y Quickbird fueron estudiadas e interpretadas por el 


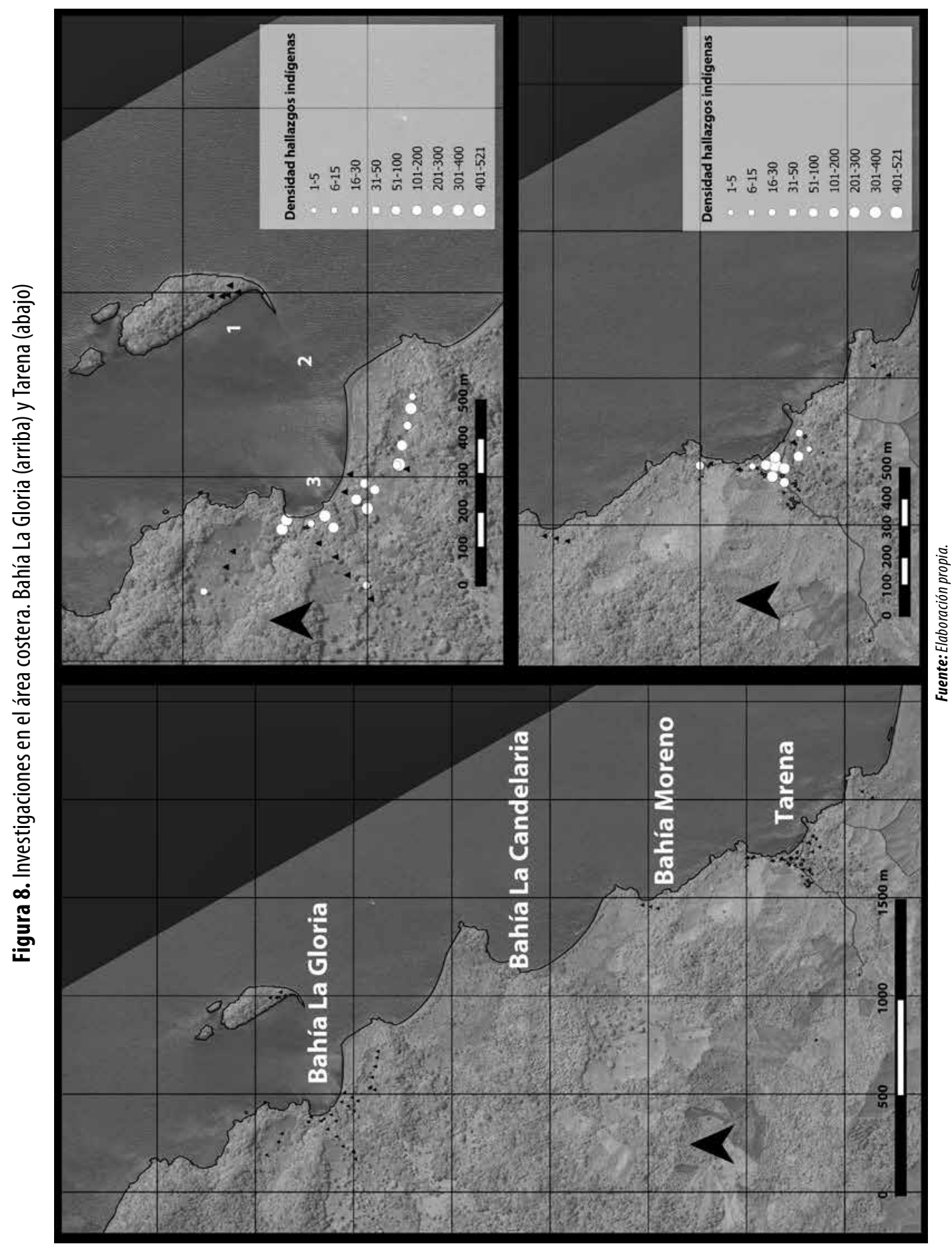


equipo de ArcSAT de Padua, Italia. En un área de aproximadamente $45 \mathrm{~km}^{2}$ se le dio prioridad al mapeo de la paleohidrografía principal, a las parcelaciones agrícolas con enfoque en las mallas regulares todavía visibles en el territorio y a las soil y crop marks presentes en el área. Algunas de las anomalías poligonales encontradas fueron estudiadas en terreno durante la expedición del 2014 y resultaron ser el producto de una actividad antrópica relativamente reciente (Sarcina 2015).

En cuanto a la paleohidrografía de la región, el estudio de las imágenes satelitales nos ha permitido elaborar algunas hipótesis reconstructivas, en particular relacionadas con el cauce original del río Darién (hoy Tanela). Las fuentes relatan que el río Darién desembocaba directamente en el mar Caribe y pasaba justo al lado de las casas de la ciudad.

En el jueves diez dias del dicho mes y año (10.10.1532) nos partimos para el Darién, el cacique con veinte y seis indios en su canoa, y allegamos al dicho puerto viernes en la tarde. Y otro dia después de comer nos fuimos el rio arriba del Darién [...] y fuimos a donde solía ser el pueblo. (Friede, 1955-1960, II, doc. 401)

[...] estuvo allí el armada el dia que llegó y el siguiente, y el tercero se partió para el Darién, y llegó al surgidero de aquella ciudad, en el golfo de Urabá, a los veinte y nueve dias del mes de junio de mill y quinientos y catorce años. (Fernández de Oviedo, Historia, vol. 3, lib. XXIX, cap. VII)

A los treynta de junio de mill y quinientos catorce años [...] saltó Pedrarias en tierra y entró en la ciudad de Sancta Maria del Antigua del Darién con toda la gente que llevaba del armada [...].

[...] y estaba muy gentil población, y con un hermoso río que passa pegado a las casas de la ciudad, de muy buena agua y de muchos buenos pescados. Este es el río del Darién, y no el que en el libro XXVII el licenciado Vadillo llama río del Darién, y este viene de la parte del Hueste, y el quél dice es un brazo del rio de Sanct Johan, que entra en la culata del golfo de Urabá, como la historia ya lo ha dicho. (Fernández de Oviedo, Historia, vol. 3, lib. XXIX, cap. VIII)

En la cartografía histórica, la desembocadura del Tanela/Darién aparece claramente sobre el mar Caribe (figura 9).

Para los fines de nuestra investigación es muy importante conocer el antiguo cauce del río Tanela y las antiguas líneas de costa para determinar, entre otras cosas, la ubicación exacta del puerto del Darién y los límites del poblado. Actualmente, el Tanela corre a unos $500 \mathrm{~m}$ del sitio arqueológico y desemboca en el río Atrato, a través de la ciénaga de Marriaga. 
Figura 9. Detalle del Mapa marítimo del Reyno de Tierre Firme ú Castilla del Oro, 1785. El río Tanela aparece como R. Tarena

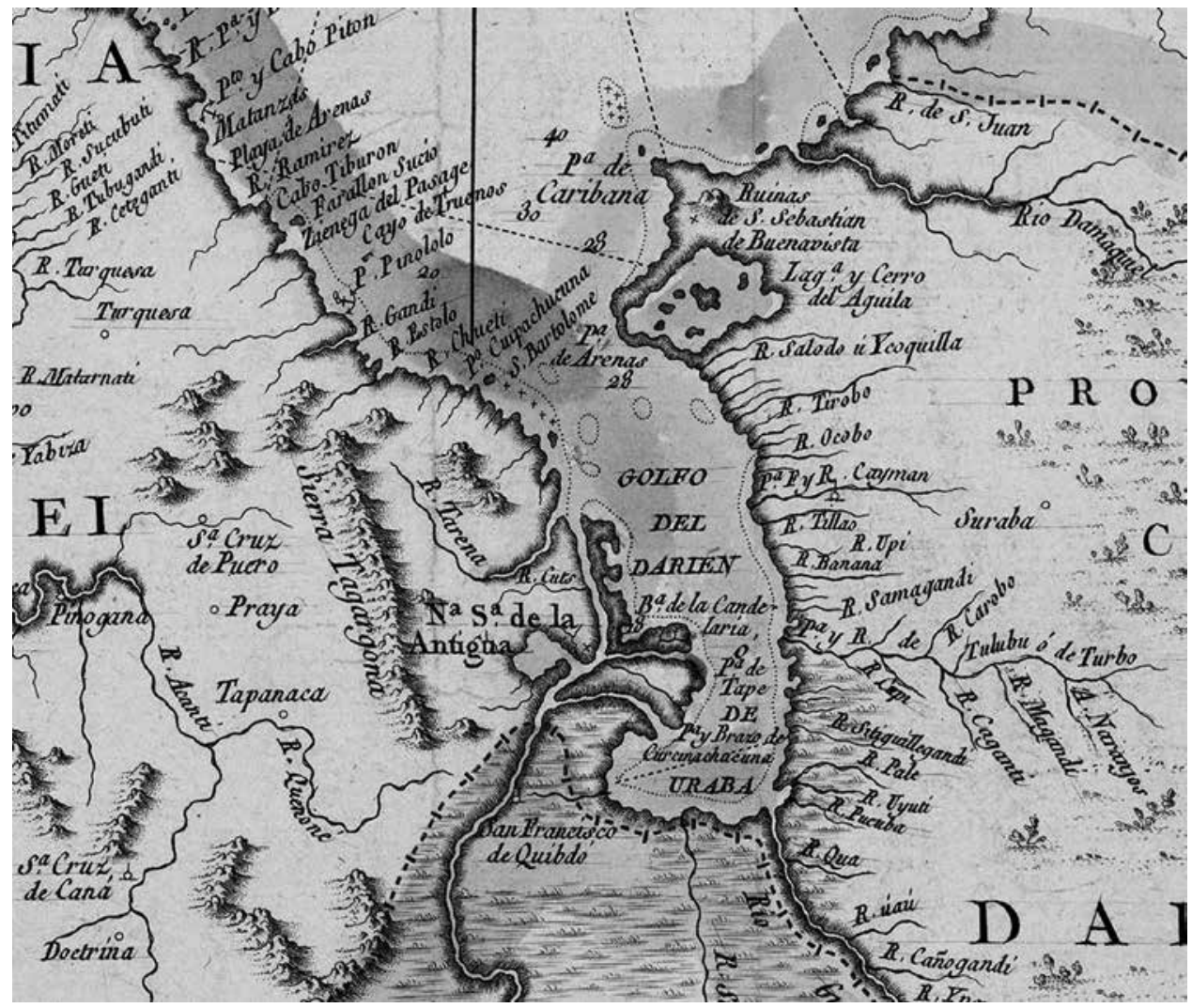

Fuente: "Carta Maritima del Reyno de Tierra Firme ú Castilla del Oro", de Juan López, 1785. Imagen de dominio público.

De la primera descripción de 1532 mencionada, es bastante claro que el puerto no podía estar muy lejos de la desembocadura del río. Como hemos visto, de los resultados de las investigaciones subacuáticas, al parecer Bahía La Gloria, con su isla y el camellón entre ambas, no presenta hasta el momento ningún tipo de evidencia española aunque tuviera una conformación aparentemente perfecta para ser un puerto. Al analizar los resultados, se puede distinguir un cauce principal del río entre los posibles paleocauces del Tanela y sus afluentes, lo cual nos permite proponer una primera hipótesis reconstructiva para el curso original del Darién, con desembocadura en el Atlántico (figura 10, arriba). Pascual de Andagoya, que vivió en la ciudad desde 1514, menciona que Santa María de la Antigua quedaba "legua y media de la mar" (Andagoya 1986), que correspondería a 8,4-8,8 km, exactamente la longitud del supuesto cauce. 
Figura 10. La paleohidrografía en las imágenes satelitales e hipótesis reconstructivas del antiguo cauce del río Darién

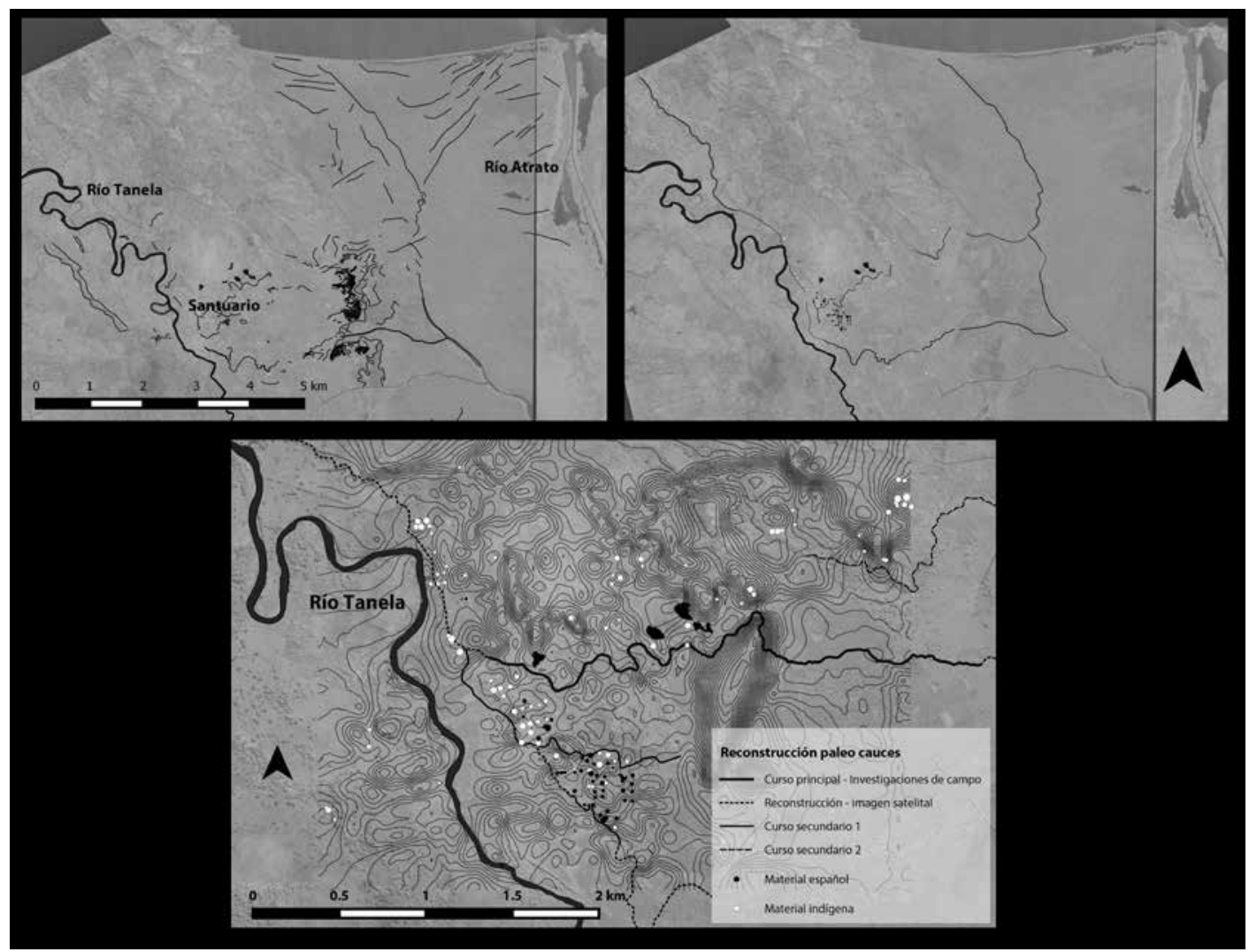

Fuente: Elaboración propia.

También es interesante observar cómo las zonas con mayor concentración de artefactos encontrados durante los trabajos de prospección (factor indicativo de asentamientos o lugares de frecuentación) son casi siempre adyacentes a, o están en, las proximidades de estos antiguos cauces de cursos de agua.

En el transcurso de la expedición del 2014 fue posible mejorar los resultados de estas investigaciones con reconocimientos en campo (Sarcina 2015). El tercer mapa de la figura 10 muestra los resultados de esta investigación, con la superposición de los resultados de las prospecciones por pozos de sondeo: la ciudad de Santa María de la Antigua del Darién aparece asomada sobre un brazo del río y atravesada por otro brazo secundario. El curso principal del Darién corría en la margen noroeste de la ciudad. 


\section{Consideraciones finales}

Los resultados de este primer trabajo arqueológico sistemático en las áreas objeto de estudio han sido considerables. Las dos preguntas principales de nuestra investigación han recibido una respuesta y hemos obtenido datos adicionales valiosos. Al reunir toda la información recogida estamos en condiciones de determinar la ubicación y los límites de la ciudad española de Santa María de la Antigua y del poblado indígena del Darién donde se instalaron los españoles al mando de Balboa y Enciso. El material encontrado y el tamaño del sitio arqueológico son perfectamente concordantes con los de una ciudad española de principios del siglo XVI.

En cuanto al puerto de Santa María de la Antigua del Darién, aunque sea difícil dar una respuesta definitiva, las posibilidades de que estuviese ubicado en Bahía La Gloria han disminuido considerablemente a la luz de los resultados de la investigación subacuática y de las prospecciones por pozos de sondeo. Estas prospecciones y las investigaciones complementarias llevadas a cabo en el transcurso de la expedición arqueológica del 2013 nos han proporcionado datos que conducen a la identificación y localización de otros dieciséis asentamientos prehispánicos posibles en la zona (figura 11): el asentamiento cerca del actual cementerio (3), en relación probable con el asentamiento del Darién por su cercanía y la homogeneidad del material cerámico; los dos asentamientos de Muribá (7) en la finca Villegas, el más septentrional de los cuales probablemente era de grandes dimensiones; los dos asentamientos de Las Minas (5) en la finca La Francia, de los cuales el más meridional posiblemente era extenso; las cinco áreas residenciales pequeñas, tal vez relacionadas con un único asentamiento disperso en la finca Hoyos (6); el asentamiento cerca de Tanela Viejo (4); el asentamiento probable en las proximidades del río Tisló y los otros dos sitios pequeños en la ribera occidental del río Tanela (8); el importante asentamiento costero de Tarena (9), y el asentamiento de Bahía La Gloria (10), ya estudiado en parte por Correal y Pinto (1983).

El estudio de las imágenes satelitales también ha producido algunos resultados preliminares muy valiosos, con hipótesis interesantes para futuras investigaciones. La reconstrucción de la paleohidrografía ha propuesto una línea de investigación sobre los límites occidentales de la ciudad y la ubicación de su puerto fluvial. Nos indica también una disposición geográfica de los asentamientos prehispánicos casi siempre en relación con los antiguos cursos de agua de la zona.

La información obtenida a partir del estudio de las anomalías rectangulares y poligonales ha abierto nuevos escenarios de posibles áreas de investigación. 


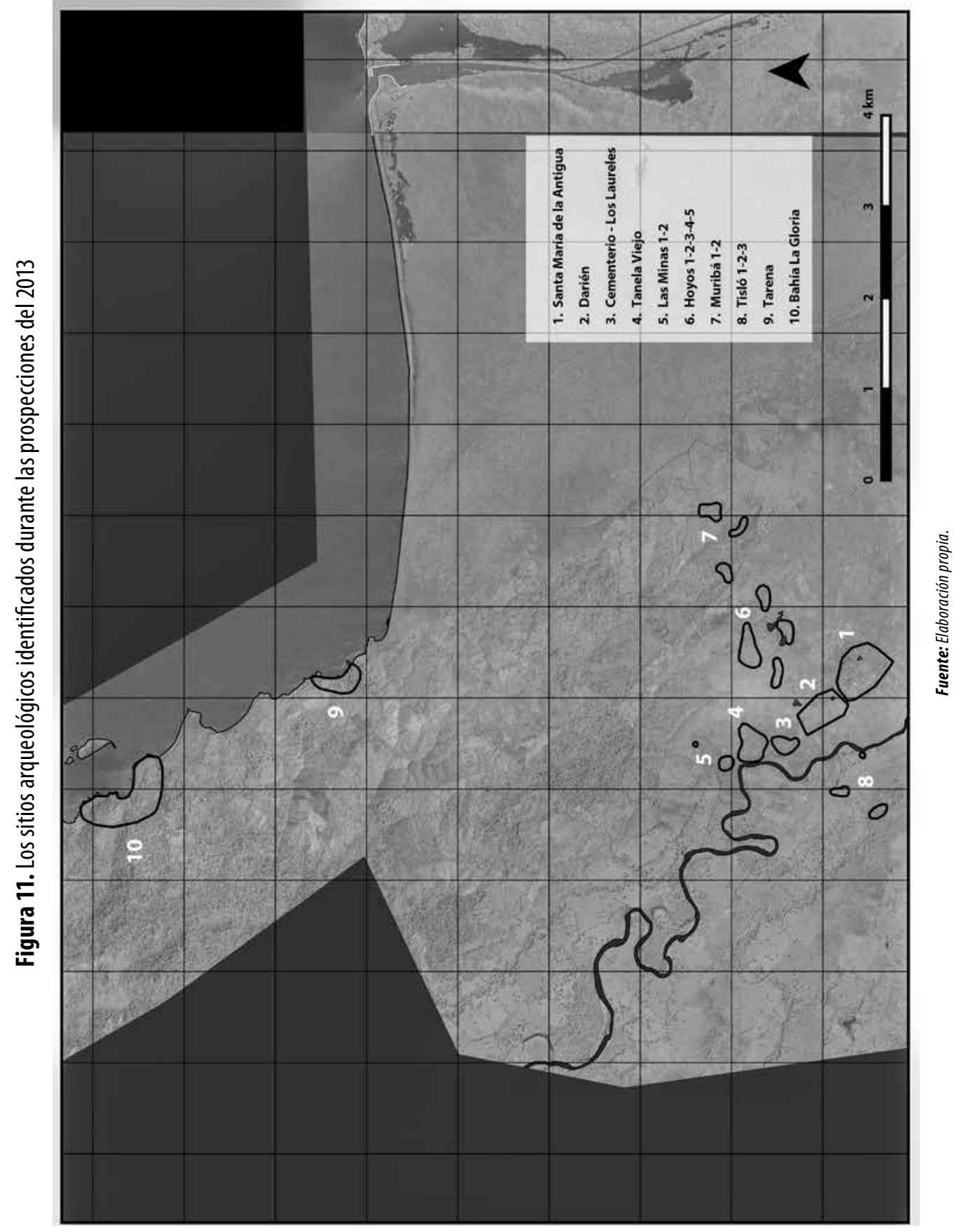


De estas, la más llamativa es quizá la relativa a las posibles estructuras vinculadas con el antiguo puerto sobre el Atlántico, no lejos de la desembocadura original del río Darién. El estudio de las divisiones agrícolas también ofrece algunos datos importantes que tendrán que ser investigados sistemáticamente. En términos de nuestro proyecto, el más importante es la parcelación de tierras identificadas en el área de Santa María de la Antigua, que podría ser un rastro de la división de la ciudad en solares.

El resultado principal de la expedición arqueológica del 2013 fue identificar y confirmar la existencia no solo de la ciudad española de Santa María de la Antigua del Darién, sino de toda una agregación de asentamientos prehispánicos dentro de un área de alrededor de $8 \mathrm{~km}^{2}$. Por otra parte, mediante el estudio de las imágenes satelitales, se han demostrado rastros de otros posibles asentamientos adicionales en un área mucho más amplia. A juzgar por los datos con los que contamos, podemos vislumbrar una región densamente poblada, por lo menos en el periodo anterior a la llegada de los españoles, especialmente en las zonas altas, casi siempre en las inmediaciones de los cursos de agua y en las costas. Esto confirmaría el relato de las fuentes.

Estos indios tienen sus asientos, algunos cerca de la mar, y otros cerca del río o quebrada de agua, donde haya arroyos y pesquerías, porque comúnmente su principal mantenimiento y más ordinario es el pescado, así porque son muy inclinados a ello, como porque más facilmente lo pueden haber en abundancia [...]. La forma de cómo pescan es con redes, porque las tienen y saben hacer muy buenas de algodón [...]. (Fernández de Oviedo, 1950, Sumario, cap. X)

Santa María de la Antigua del Darién no habría sido fundada, según esta interpretación, en un territorio de selvas impenetrables, sino más bien en un entorno fuertemente antropizado, aunque solo las excavaciones estratigráficas en el área podrán confirmar que se trata de asentamientos contemporáneos a la llegada de los españoles. Según Kathleen Romoli (1987, 32), esta zona corresponde a la margen oriental del territorio de habla cueva, no muy poblada, ya que de acuerdo con las fuentes solo se conocen dos cacicazgos, el del Darién y el de Careta. Por otro lado, Linné (citado por Romoli) señala que la costa entre La Gloria y el bajo delta del Atrato estaba densamente poblada. Además, Fernández de Oviedo, que vivió por muchos años en Santa María de la Antigua, dice que "es verdad que los indios que en aquella sazón había en aquella gobernación, pasaban de dos millones, o eran incontables” (Historia, vol. 3, lib. XXIX, cap. IX).

Estos resultados abren una perspectiva de investigación arqueológica "regional”, orientada no solo al estudio de los asentamientos conectados al sistema 
económico (de intercambio y explotación) en el que Santa María de la Antigua del Darién fue el centro, sino también de aquellos asentamientos que pertenecen a diferentes horizontes culturales y marcos cronológicos. En este sentido, apoyamos decididamente la propuesta de algunos investigadores (i. e. Martín-Rincón 2002) de aunar esfuerzos para el estudio de la región que muchos investigadores definen como Gran Darién (Bray 1984, Cooke 1976, Cooke y Sánchez 2004) y que comprende el área entre el río Atrato y Chamé, al occidente del actual canal de Panamá.

\section{Agradecimientos}

Quisiera agradecer al Ministerio de Cultura de Colombia y al Instituto Colombiano de Antropología e Historia (ICANH) por promover y financiar el proyecto y, en especial, a Ernesto Montenegro, director del ICANH y del proyecto multidisciplinar que condujo a la creación del Plan de Manejo y Protección, y a la declaración en el 2015 de Santa María de la Antigua del Darién como Bien de Interés Cultural de la Nación. También agradezco a Paolo Vignolo, director del componente histórico del proyecto y uno de sus creadores, y a la Fundación Trenza por la coordinación del proyecto. El estudio de las imágenes satelitales fue realizado por Andrea Betto y Vincenzo Valente de la sociedad ArcSat de Padua. La prospección terrestre en La Gloria y Tarena estuvo a cargo de Marcela Manrique y la prospección subacuática en La Gloria fue realizada bajo la coordinación de Juan Guillermo Martín. Agradezco especialmente a las comunidades de Santuario, Citará, Tanela y Tarena, sin cuyo apoyo jamás hubiera sido posible realizar este trabajo.

\section{Referencias}

Ammerman, Albert. 1981. "Surveys and Archaeological Research”. Annual Review of Anthropology 10: 81-82.

Andagoya, Pascual de. 1986. Relación y documentos. Madrid: Historia 16.

Arcila Vélez, Graciliano. 1986. Santa María de la Antigua del Darién. La primera ciudad de la América continental y la primera sede episcopal de América. Bogotá: Presidencia de la República, Secretaría de Información y Prensa.

Avery, George. 1997. "Pots as Packaging: The Spanish Olive Jar and Andalusian Transatlantic Commercial Activity, 16th-18th centuries”. Disertación doctoral, University of Florida. Gainesville, Florida. 
Bedoya, María del Carmen y María Eugenia Naranjo. 1985. Reconocimiento arqueológico en el litoral atlántico: Capurganá. Informe inédito. Medellín: Fundación de Investigaciones Arqueológicas Nacionales, Banco de la República.

Bray, Warwick. 1984. "Across the Darien Gap: A Colombian View of Isthmian Archaeology”. En The Archaeology of Lower Central America, editado por Frederick W. Lange y Dorois Z. Stone, 305-338. Albuquerque: University of New Mexico.

Cambi, Franco y Nicola Terrenato. 1994. Introduzione all'archeologia dei paesaggi. Urbino: NIS.

Cooke, Richard. 1976. “Panamá: región central”. Vínculos 2 (1): 122-140.

Cooke, Richard y Luis Alberto Sánchez Herrera. 2004. "Las sociedades originarias”. En Historia general de Panamá, editado por Alfredo Castillero Calvo, 2-89. Panamá: Comité Nacional del Centenario de la República de Panamá.

Correal, Gonzalo y María Pinto. 1983. "Evidencia de cazadores especializados en el sitio de La Gloria. Golfo de Urabá”. Revista de la Academia Colombiana de Ciencias Exactas, Físicas y Naturales XV (58): 77-82.

Deagan, Kathleen. 1987. Artifacts of the Spanish Colonies of Florida and the Caribbean, 15001800, vol. 1. Washington, D. C.: Smithsonian Institution.

Fairbanks, Charles H. 1966. “A Feldspar-Inlaid Ceramic Type from Spanish Colonial Sites”. American Antiquity 313: 430-432.

-. 1972. "The Cultural Significance of Spanish Ceramics”. En Ceramics in America, editado por George Irving Quimby, 141-174. Charlottesville: University of Virginia Press.

Fernández de Oviedo y Valdés, Gonzalo. (1526) 1950. Sumario de la natural historia de las Indias. México D. F.: Fondo de Cultura Económica.

-. (1535) 1851-1855. Historia general y natural de las Indias, islas y Tierra Firme del mar Océano. 4 t. Madrid: Imprenta de la Real Academia de la Historia.

Florida Museum of Natural History (FLMNH), Historical Archaeology. 2015. Consultado el 12 de noviembre del 2015. http://www.flmnh.ufl.edu/histarch.

Friede, Juan, ed. 1955-1960. Documentos inéditos para la historia de Colombia. 9 vols. Bogotá: Academia Colombiana de Historia.

Goggin, John. 1960. The Spanish Olive Jar: An Introductory Study. Yale University Publications in Anthropology 62. New Haven: Yale University Press.

-. 1968. Spanish Majolica in the New World. Yale University Publications in Anthropology 72. New Haven: Yale University Press.

González Escobar, Luis Fernando. 2011. El Darién. Ocupación, poblamiento y transformación ambiental. Una revisión histórica, parte I. Medellín: Instituto Tecnológico Metropolitano.

Lister, Florence C. y Robert Lister. 1987. Andalusian Ceramics in Spain and New Spain: A Cultural Register from the Third Century B. C. to 1700. Tucson: University of Arizona Press.

Martín-Rincón, Juan Guillermo. 2001. "Pisos coloniales en Panamá la Vieja: una manera de afianzar el status”. En Arqueología de Panamá La Vieja, 225-238. Panamá. https://www. 
academia.edu/1762707/Pisos_coloniales_en_Panam\%C3\%A1_La_Vieja_una_manera_de_ afianzar_el_status.

-. 2002. Panamá La Vieja y el Gran Darién. En Arqueología de Panamá La Vieja, 230-250. Panamá. Disponible en http://panamaviejo.org/patronato/reportes_campo/grandarien.PDF.

Mena García, Carmen. 2011. El oro del Darién. Entradas y cabalgadas en la conquista de Tierra Firme (1509-1526). Sevilla: Fundación Pública Andaluza, Centro de Estudios Andaluces, Consejería de la Presidencia y Junta de Andalucía.

Roda, Cristóbal de. 1609. Mapa de Panamá, Archivo General de Indias, ref. Panamá 27, Sevilla.

Romoli, Kathleen. 1987. Los de la lengua cueva. Bogotá: Instituto Colombiano de Antropología.

Santos Vecino, Gustavo. 1982. "Segunda campaña de investigaciones arqueológicas y prehistóricas en la región del golfo de Urabá”. Cuadernos de Antropología 2: 1-81.

Steiner, Claudia. 1991. "El rey Leopoldo de Bélgica en Urabá: una expedición a Santa María de la Antigua del Darién en 1956”. Revista Credencial Historia 21. http://www.banrepcultural.org/node/32954.

Vignolo, Paolo y Virgilio Becerra, eds. 2011. Tierra Firme: el Darién en el imaginario de los conquistadores. Bogotá: Instituto Colombiano de Antropología e Historia; Universidad Nacional de Colombia. 